\title{
) Mesta e intereses ganaderos en el Buenos Aires tardocolonial (1772-1794)
}

Lucio B. Mir'

Durante los últimos quince años hemos asistido en la Argentina a una sustancial renovación historiográfica cuyas edificantes consecuencias para la labor científica difícilmente alguien pueda poner en tela de juicio. Así, por ejemplo, las conclusiones acerca del estudio de la mano de obra rural en el Río de la Plata, especialmente centradas para la segunda mitad del siglo XVIII y comienzos del XIX, constituyen una clara evidencia de ese significativo avance en la investigación. Lo que ahora sabemos respecto de la fuerza de trabajo y de los sectores dominantes de la campaña bonaerense y de la Banda Oriental representa un notorio progreso en los conocimientos sobre la sociedad y economía rural del espacio rioplatense. En efecto, contamos con valiosos aportes que han enriquecido una realidad considerablemente más compleja que la presentada por la historiografía tradicional; en esa renovación, cuyos antecedentes se encuentran en trabajos de Tulio Halperín Donghi (1994), destacan Carlos Mayo (1984), Jorge Gelman (1989 y 1998), Juan Carlos Garavaglia y José Luis Moreno (1993), Juan Carlos Garavaglia (1989,1993), Raúl Fradkin (1987), Ricardo Salvatore y Jonathan Brown (1993), por citar tan sólo algunos de los muchos investigadores que aportan a la historia agraria del Río de la Plata.

1- Departamento de Historia, Facultad de Ciencias Humanas. UNLPam. 
Una renovación historiográfica que ha permitido derribar varios mitos, entre ellos, el forjado alrededor del rol ejercido por los sectores rurales de Buenos Aires dentro de la estructura de poder, impugnando el arraigado consenso que postulaba, respecto a los más ricos e influyentes hacendados, haber detentado un apreciable poder político durante las últimas décadas del período colonial ${ }^{2}$.

En este trabajo, inscripto en dicha renovación, proponemos reabrir el debate en torno a ciertos elementos que problematizan sobre las contradicciones de los estancieros en su dinámica de articulación con otros sectores de la sociedad y con el Estado, sus dificultades para fortalecer su inserción orgánica en las estructuras institucionales y la centralidad del Estado en tanto árbitro supremo regulador del ejercicio de la dominación política.

\section{Los comerciantes-hacendados}

La identificación de procesos gravitantes en el plano político-institucional e inherentes a la compleja problemática del mundo agrario requiere reconsiderar ciertos planteamientos y formular nuevos interrogantes sobre ángulos insuficientemente estudiados. Por tal motivo, creemos pertinente adelantar algunas ideas relacionadas a la índole de la estructura de poder con intereses en la ganadería de Buenos Aires. Tales ideas no persiguen otra finalidad que la de fundamentar un trabajo aproximativo, simple punto de apoyo al servicio de una reflexión que necesariamente deberá ser más amplia y profunda.

El período considerado, es decir 1772-1794, se inscribe en un contexto económico cuya característica preponderante está definida por la expansión de las exportaciones de cueros bovinos (Montoya, A. 1984:111) y el crecimiento del mercado urbano.

Nuestro objetivo principal es avanzar en el análisis de la influencia que han ejercido ciertos factores condicionantes, en el marco de una compleja interrelación de intereses urbano-rurales, sobre la gravitación/actuación de los miembros especializados del grupo hacendado (grandes estancieros dedicados predominantemente a la ganadería), en tanto parte de la clase terrateniente en formación. Pero antes de realizar algunas observaciones sobre el comportamiento corporativo de estos intereses es necesario distinguir los espacios de

2- La tesis de unos hacendados bonaerenses convertidos en "clase social" con "reconocido prestigio y fuerza" se encuentra en el clásico libro de Horacio Giberti. (1986:60). El primer historiador en realizar un serio cuestionamiento a esta interpretación fue Halperin Donghi (1994:41-45) 
poder, para lo cual resulta preciso reconocer específicas características que definen la posición de los denominados comerciantes-hacendados.

Un primer elemento a tener en cuenta es que estos comerciantes-hacendados -grupo mercantil con intereses en la tierra- eran una minoría que Carlos Mayo ha conceptualizado como "sector especial" dentro del grupo estanciero (Mayo, Carlos A. 1995:64), sector perteneciente a la elite porteña y dominante en el comercio; actividad que, por otro lado, ha determinado la naturaleza de su formación, mecanismos de acumulación y/o reproducción. (Gelman, 1989). Comerciantes-hacendados como Antonio Romero, Santiago Saavedra, Antonio Obligado, Felipe de Argivel y Joaquín Cabot residían en Buenos Aires y participaban en el Cabildo y el Gremio de Hacendados.

En cuanto a los orígenes de este gremio, el primer paso significativo para organizar la corporación de ganaderos se concretó durante la Junta General del 2 de diciembre de 1775, oportunidad en que fueron establecidos dos niveles de conducción: el apoderado y la junta. El apoderado fue quien de hecho concentró la representación gremial. De la junta de 1775 surgió un grupo de poder corporativo cuya limitada, aunque no desdeñable influencia se observa nítidamente en el Cabildo, ámbito donde los comerciantes ejercían un completo control. Según Fradkin, de los diez diputados electos en dicha junta cinco pertenecían a los "principales hacendados"13, vecinos de Buenos Aires y miembros de la elite. Era entonces una organización gremial que procuraba constituirse bajo la tutela de algunos integrantes del poderoso núcleo mercantil y con el apoyo de los grandes estancieros.

$Y$ respecto a la gran mayoría de los estancieros, ¿acaso podemos imaginarlos un grupo influyente? Si hemos de creer en la opinión del procurador general de la ciudad esa inveterada imagen se desvanece, pues este funcionario consideraba que:

"Los Hacendados en esta jurisdiccion á excep.on de algunos pocos [comercianteshacendados], que tienen tambien otros giros, ú establecimientos son unos pobres hombres, sin mas arbitrio, ni modo de vivir, que el que les da el producto de sus haciendas..." ${ }^{14}$.

Similar lectura realizó también en 1773 un calificado observador de Buenos

3- Véase el lúcido análisis de Raúl O. Fradkin (1987:82)

4- Representación del procurador general Manuel de Basavilbaso al Cabildo. Buenos Aires, 4/12/1773.

En: Facultad de Filosofia y Letras, Documentos para la Historia Argentina, Abastos, tomo IV, Bs. As., Compañía Sud-Americana de Billetes de Banco, 1914, p.9. 
Aires y su campaña. Según se desprende del testimonio de Concolorcorvo la situación de los estancieros era prácticamente fronteriza con la estrechez, al punto que incluso los más pudientes tenían dificultades para reunir un módico monto en metálico. Así, uno de los hacendados residentes en la ciudad porteña -a quien el viajero considera un hombre rico - disponía de un cuantioso stock ganadero, sin que ello comportara una sólida posición financiera ${ }^{5}$. El negocio pecuario no genera todavía altos beneficios a los estancieros, aunque sí al especulativo comercio de exportación (Halperín Donghi, Tulio, 197..:45), y permite entender por qué las actividades mercantiles ameritan la consagración prioritaria por parte de los vecinos, desde el momento que de allí surgían las mayores fortunas:

"No he conocido hacendado grueso, sino a don Francisco de Alzáibar, que tiene infinito ganado de la otra banda del río, repartido en varias estancias; con todo, mucho tiempo ha que en su casa no se ven cuatro mil pesos juntos. No he sabido que haya mayorazgo alguno ni que los vecinos piensen más que en sus comercios, ..."

Como puede advertirse, el "reconocido prestigio y fuerza" adjudicado hasta hace no tanto a los estancieros se diluye ante la atenta lectura de las fuentes, un hábito poco usual entre los ensayistas que construyeron esa imagen terrateniente tan difícil de desmontar. Imágen que, conviene poner énfasis, surgió de proyectar al período colonial las condiciones sociopolíticas de una elite que, sin duda desde las últimas décadas del siglo XIX, gozaría de enorme prestigio y poder.

Ahora bien, ¿cómo penetraba en la campaña el poder del Estado? Es sabido que la potestad político-jurisdiccional ejercida sobre el espacio rural se efectivizaba -a excepción del distrito bajo competencia de la villa de Luján- a través

5- A mediados del siglo XVIII un médico escocés que visitó Buenos Aires se asombra de que fuera "...posible adquirir una tropilla de ganado vacuno o caballar a cuatro reales la cabeza". Y luego agrega "Un hombre poseedor de diez mil cabezas de ganado fino no es considerado, por lo tanto, rico en este país". Ver este testimonio anónimo en "Viaje al Rio de la Plata y Chile (1752-1756)". En Revista de la Junta de Estudios Históricos de Mendoza, Mendoza, Segunda Epoca, N99, tomo II, 1980, p.362.

6- Concolorcorvo [Alonso Carrió de la Vandera], "El lazarillo de ciegos caminantes" [1773]. En: Biblioteca de Autores Españoles, Relaciones histórico-literarias de la América meridional, tomo CXXII, Madrid, Ediciones Atlas, 1959, p.294. A principios de 1771, un funcionario informaba a la Corona que el ganado bovino "...á llegado á numero ingraduable, pero tan inutil que un Nobillo de seis ó siete años no tiene mas precio que cl del balor de su cuero que no sube a un Peso,...". Véase el memorial de Antonio Josef del Castillo. En: Facultad de Filosofía y Letras, Documentos para la Historia Argentina, Comercio de Indias, Antecedentes Legales, tomo V (1713-1778), Bs. As., Compañía Sud-Americana de Billetes de Banco, 1915, p. 260. 
del Cabildo de Buenos Aires, institución subordinada a los intereses de los comerciantes de la ciudad, quienes controlaban resortes significativos de la estructura de poder. Así, la campaña porteña, importante abastecedora de carnes para el mercado urbano y de cueros para la exportación, estaba sometida a grupos de poder cuyos intereses fundamentales no se encuentran en el campo. El fenómeno es conocido aunque resulta preciso profundizar sobre los móviles de los grandes hacendados (quienes, excepto el "sector especial", tenían una ubicación marginal en las relaciones de poder) en su afán por dotarse de un consistente aparato de representación corporativa, a cuya consecución ya habían dirigido sus primeros pasos con la organización de un gremio.

Finalidad nunca alcanzada y, por lo demás, perseguida enfrentando recurrentes crisis cuyas causas se explican a partir de la escasa cohesión, homogeneidad y solidaridad endógena exhibida por estos hacendados (Fradkin, Raúl, 1987: 83-84). En 1783 y 1788 se celebraron dos juntas para zanjar las dificultades de representación que minaban la posibilidad de formalizar una sociedad plenamente orgánica. Trataban, por tanto, de cerrar filas frente a la pronunciada incidencia de factores de dispersión y convenir cierta unidad de intereses en procura de balancear, siquiera parcialmente, la desfavorable posición que detentaban dentro de la estructura de poder.

Una de las prioridades de los grandes estancieros era resolver el problema de la inserción orgánica en esa estructura de poder, y fue por ello que la necesidad de construir su hegemonía en el medio rural devino clave para escapar de la perniciosa ubicación que las condiciones estructurales de la campaña volvían ineluctable. El proyecto de construcción de dicha hegemonía tropezaba básicamente con la debilidad y conflictos de los hacendados y, en menor medida, con el contradictorio comportamiento del Estado, árbitro supremo e instrumento de la política metropolitana, por lo general poco permeable a las demandas de los sectores rurales. La actividad estatal consistió en desarrollar su gestión armonizadora bajo la premisa de garantizar formas estables de articulación entre grupos cuyos intereses no siempre resultaban convergentes. Si el Estado intervenía fue porque también debió asegurar el normal funcionamiento de los canales de abasto al mundo urbano y, sobre todo a lo largo de la década de 1790, debido al aumento del interés por la propiedad de la tierra y la producción agropecuaria. Sus funciones procuraron hacerse compatibles con las oportunidades y expectativas resultantes de la acelerada incorporación del Río de la Plata al mercado mundial.

Más aún, otro objetivo prioritario de los estancieros -cuya viabilidad estaba en gran parte supeditada al propósito más general de ampliar su restringida 
influencia- consistía en superar las limitaciones legales e instrumentales que acotaban el intento de montar sólidos mecanismos de control y represión del cuatrerismo y el vagabundaje que, según los estancieros, causaban serios problemas en el desarrollo de sus actividades. Sin embargo, los propios hacendados no fueron totalmente ajenos a una conducta que a su vez no vacilaron en combatir, pues el hurto de ganados resultaba práctica corriente entre quienes eran considerados por el poder como legítimos estancieros. No sorprende entonces que las autoridades fustiguen a esos:

"...Azendados [que] venden y matan, no solo los Toros y Novillos desu Marca, sino los agenos y agenas; todo lo qual es contra la causa publica; y contra la subsistencia del florido Ramo de Comercio de Cueros,..."

¿Cómo contrarrestar el comportamiento inorgánico cuanto no anárquico de estos hacendados? ¿Qué mecanismos más eficaces podrían montarse para operar sobre el conflictivo contexto dominante en el medio rural? Conocido es que la justicia colonial no respondía satisfactoriamente a las demandas planteadas por los estancieros (Mayo Carlos, 1995:162) y ese factor adverso se tradujo en la favorable disposición del Cabildo para encauzar el establecimiento de un organismo que, entre sus diversas funciones, tuviera mayores facultades para el resguardo del orden y la seguridad de la campaña.

\section{Vagos y malentretenidos}

En este escenario de crisis de representación del Gremio de Hacendados puede explicarse el proyecto para constituir la Hermandad de la Mesta ${ }^{8}$. Según la institución capitular promotora de la iniciativa, una sociedad de esta índole:

"...no es otra cosa que una Asamblea, ô congregación compuesta de los Proprios Hacendados, autorizada para discurrir los medios de custodiar, y aumentar los Ganados, persiguiendo los Ladrones, y allanando todo lo que se oponga á tan recomendable objeto, por medio de los Alcaldes, que deven elegirse de este proprio Cuerpo, y de las

7- Representación del fiel ejecutor, don Gregorio Ramos Mexia. Buenos Aires, 24 de marzo de 1783. En: Documentos para la Historia Argentina, Abastos, tomo IV, op. cit., p.44.

8- "Estas y otras causas sirvieron al Cabildo para fundar su proyecto del establecimiento de la Hermandad de la Mesta, que, a su juicio, sería la institución encargada de evitar la ruina de la ganadería". Ver Levene, Ricardo. Investigaciones acerca de la historia económica del Virreinato del Plata, La Plata, Biblioteca Humanidades, vol.II, 1928, p.77. 
Ordenanzas / que formase la misma Hermandad con precedente aprovacion de la Superioridad..."1.

En la sesión del 12 de marzo de 1790 el Cabildo aprobó por unanimidad el proyecto $^{10}$. Conforme a las miras declaradas consistía en una institución corporativa dirigida por un grupo de hacendados a efectos de proteger, articular y coordinar intereses comunes en torno a la ganadería", frente a la acción de diversos factores que escapaban a la eficacia del poder de policía conferido al Cabildo, en tanto principal institución actuante del Estado respecto del ámbito rural. Tales factores son de diversa naturaleza, pues van desde la predación de los perros cimarrones hasta los específicamente político-legales, es decir, relativos a la acción delictiva. Estos últimos resultan pertinentes al objeto de nuestra indagación. A fines de 1788 el Cabildo consideraba que:

"... limpia la Campaña de unas gentes tan perjudiciales, y celando la introduccion de otras, no solo se conseguirá una gran quiet.d en ella, sino que libre de ladrones si sucediese algun robo de Ganado Bacuno, Mulas, y Caballos, se podra con facilidad asegurar el Ladron, estando prevenidos todos / los Jueces, y Cabos Militares de la Campaña..."

"...para impedir que los Indios maten las terneras como acostumbran para su Comercio se prohiba que los Pulperos, ó qualesquiera otra persona, les compren las botas guacipicuas, ó pellejos que trahen a vender de esta expecie de Ganados, pues con este medio suave, se cortará sin exasperarlos, este perjudicial abuso"12.

La proliferación de pulperías en la campaña constituía una seria amenaza para los grandes estancieros, desde el momento que eran vistas como núcleos de articulación a través de los cuales grupos subalternos de esta heterogénea e inestable sociedad rural canalizaban el producto de sus abigeatos. (Marquiegui Didier, 1990). Por otra parte, el andamiaje jurídico montado para neutralizar las

9-Acta del Cabildo de Buenos Aires, 12/3/1790. En: Archivo General de la Nación, Acuerdos del Extinguido Cabildo de Buenos Aires, serie III, tomo IX, Bs. As., Guillermo Kraft Ltda., 1931, p.293. 10-Consta en acta el haberse remitido el testimonio del acuerdo al virrey Arredondo para su "Superior aprovacion". Ibídem, p.294.

11-Klein, Julius (1990). La primera edición castellana es de 1936. En cuanto a la difusión de la Mesta en América española, Konetzke ha sostenido: "Aunque originariamente la corona había abrigado la intención de introducir la mesta en todas las partes de su imperio indiano, ese organismo de los ganaderos quedó restringido a México". Véase Konetzke, Richard (1983:299)

12-Acta del Cabildo, 14/11/1788. Acuerdos..., serie III, tomo VIII, Bs. As., 1930, pp.675-682. 
actividades de un gran número de traficantes, incluidos algunos extranjeros, resultó un esfuerzo estéril si consideramos la repetición de bandos y ordenanzas con que las autoridades pretendieron enfrentar este complejo problema:

"Que se manden retirar todos los mercachifles particularmente Extrangeros que andan en las Campañas por los practicos perjuicios q.e ocacionan, y que no se consientan Pulperos fijos, sino en el recinto de la Poblacion de la Parroquia, ó Capilla de cada Partido, y que para impedir la perjudicial livertad con que se tiene comprehendido cambalachan sus efectos por Cueros, grasa, y Sevo con / personas que no son capaces de manejar estas expecies, porque no tienen haciendas que se las produzgan se les prohivan estos Cambalaches, y Cambios..."13.

Igual inquietud generaba el desarrollo de un campesinado independiente, cuya capacidad para competir con los grandes hacendados era tal vez el factor más irritativo porque restaba oferta a los requerimientos de fuerza de trabajo y, consecuentemente, la encarecía:

"Que respecto á experimentarse, q.e muchos sin poseher el terreno competente para Estancias, se han hecho de crecido numero de Ganado, y que estos como el Campo de su respectivo dueño es muy limitado salen de el, y se estienden por los circunvecinos en perjuicio de los amos de ellos, y sus haciendas, se declare, q.e ninguno pueda tener Estancia, ni tenerse por Criador, sino el q.e posea tres mil varas de terreno por frente, $y$ legua, y media de fondo conforme al repartimiento primitivo de la fundación de esta Ciudad, y sea obligado á venderlo a los circunvecinos q. quisieren comprarlo"14.

Este cuadro de situación también afectaba a la campaña sometida al distrito del Cabildo de Luján, por lo que resulta necesario indagar respecto a la posible coordinación de políticas represivas entre ambos ayuntamientos. Para contrarrestar los efectos de estos factores condicionantes, responsables de

"...un desorden que jamas se ha visto..."15 y favorecer la consecución de sus objetivos fundamentales, el Cabildo porteño promueve, ante las presiones del grupo más influyente de estancieros, la convocatoria de juntas para aunar sus intereses corporativos:

"Que para que todos los Hacendados formando un gremio respetable, puedan rep-

13- Acta del Cabildo, 14/11/1788. Acuerdos..., serie III, tomo VIII, op. cit., p.678.

14- Ibídem, p. 680.

15- Ibídem, p.670.

.16.

- Revista Quinto Sol - 
resentar, y promover sus drôs..., seria muy conveniente que vajasen todos,... pues practicandolo asi, se removerán las dificultades que frequentemente se suscitan por tenerlo de unos y nó haverselo dado otros; quedando de esta suerte autorizado por todo el que eligieren / y nombraren"16.

Hemos considerado hasta aquí la intervención del Cabildo. Los efectos de dicha injerencia fueron, en la mayoría de los casos, extremadamente limitados, lo cual creaba las condiciones para que otro poder acudiera en su auxilio sin por ello menoscabar las funciones reservadas a la institución capitular. Si bien fue el Cabildo el cuerpo involucrado en elaborar distintas estrategias de control social y laboral sobre la campaña, no menos significativo resultó -siquiera por sus futuras implicaciones sociopolíticas, la exigencia de papeleta de conchabo dispuesta por Sobremonte en 1804- el activo rol desempeñado por el virrey. Es sabido que las áreas de frontera -sometidas directamente a jurisdicción virreinal- estaban más expuestas al accionar de "vagos y malentretenidos"; en su intento por neutralizar la autonomía de estos habitantes de la campaña, el virrey Vértiz dispuso en 1779 que:

"Como tengo entendido el mucho desorden, que hay en la Campaña, y la frequencia de hunos y otros excesos no menos criminosos, encargo particularmente, y en caso necesario le doy la correspondiente comision al Comandante de Frontera, a los dos Ayudantes Mayores,... persigan con incesante inflexible vigilancia, y arresten a todo Delincuente, mal entretenido, escandaloso y Vagabundo, que residentes o transeuntes haya en sus departamentos y Partidos, prohibiendo tambien en las Estancias o Chacras los que llaman agregados..."1".

La iniciativa de Vértiz fue un intento vano y nada original por hacer sentir el peso del poder en el medio agrario. En rigor, el virrey Pedro de Cevallos ya había inaugurado apenas se hizo cargo del gobierno una modalidad radical que, pese a la índole de su carácter, no consiguió disciplinar al pobrerío de la campaña. La acción de Cevallos se materializó en la captura y requisa de unos 1.500 "vagos", número significativo que permite entrever, entre múltiples aris-

16- Ibídem, p.683. Al referirse a los inconvenientes para recaudar un tributo reclamado a los hacendados, el Cabildo sostenia que a "D.n Juan Jimenez... la maior parte no le reconosen por tal Apoderado para poder consentir en grabamenes de el Gremio, ni podran reconoserle mientras no se nombre en la Junta General propuesta p.r este Congreso al Exmo Señor Virrey...". Véase el acuerdo del Cabildo de fecha 16/12/1791. En: Documentos para la Historia Argentina, tomo IV, op. cit., p.129.

17- Instrucción que debe observar el comandante de la Frontera. Buenos Aires, 4/5/1779. Transcripta por Nellar, Fued G. (1973:197) 
tas, la magnitud del problema de la carencia de brazos. (Rock David, 1994:105).

\section{¿Una campaña fuera de control?}

Resultaba imperiosa entonces la necesidad de reforzar los instrumentos coercitivos disponibles y la Hermandad de la Mesta, en tanto concebida como institución aglutinante de los grandes intereses ganaderos -quienes según hemos visto estaban lejos de constituir un bloque monolítico- comportaba una herramienta complementaria que no se confundía con el Estado pero que buscó organizarse bajo su consentimiento y del cual esperaba, en contraparti$\mathrm{da}$, patrocinio de sus estructuras. Pretendía ser una respuesta totalizadora frente a la ineficacia de las acciones promovidas tanto por el virrey como por el Cabildo y pareció justificarse ante la urgencia de recurrir al concurso de herramientas autónomas, manejadas enteramente por los propios hacendados, aunque autorizadas por el Estado:

"Pues estrechados los Criadores con los Vinculos de una bien reglada sociedad, y alentados con su proprio interés procederan de acuerdo á purgar los Campos de todo lo que les incomode... En una palabra haciendose á los Criadores por este medio arbitros de su propria felicidad ${ }^{\mathrm{m} 8}$.

Otros grupos de hacendados gozaban de cierta autonomía política a través de su inserción en la institución capitular, como es el caso de los miembros del Cabildo de Luján, quienes controlaban ese ayuntamiento ${ }^{19}$. Los intentos encaminados a construir autonomía por parte de los grandes hacendados no resultan fácilmente rastreables en la documentación, aunque los antecedentes respecto a algunos aspectos de la iniciativa de la Mesta, destinada a fortalecer la cohesión y estabilidad orgánica de quienes conformaban el "tejado" agrario, reconocían, casi dos décadas de existencia. A juzgar por el debate entre los estancieros que peticionaban al Cabildo

"...desde el año de Setenta y dos se puso en execucion este pensamiento y hasta el

18- Acta del Cabildo de Buenos Aires, 12/3/1790. En: Acuerdos..., serie III, tomo IX, op. cit., p.293. La cursiva nos pertenece.

19-Uno de los grandes hacendados impulsores de la Mesta, Manuel Pinazo, era alcalde ordinario del Cabildo de Luján. En tal cargo se desempeñaba ya a comienzos de 1770. Véase Azcuy Ameghino $(1988: 35,36)$ 
presente se ha intentado llevar adelante..."20.

Ello a su vez se daba en un contexto de crecimiento de la población rural que generaba ciertas tensiones estructurales pero cuyo impacto territorial tendía a minimizarse como resultado de los esfuerzos particulares -y también públicos- en propiciar la expansión de la frontera. Sobre esta cuestión cabe advertir la incidencia de un fenómeno contradictorio: por un lado resultaba necesario expandir la frontera para sostener la respuesta productiva al crecimiento de la demanda local y exterior; por otro, esa expansión territorial, aun cuando fuese modesta, alimentaba al mismo tiempo el permanente acceso a la tierra de sectores subalternos y marginales, situación que reforzaba el mantenimiento de la autonomía que se buscaba combatir. En efecto, la década de 1770 contempló, en la campaña de Buenos Aires, una incesante presión de los pobladores fronterizos en su afán por ganar nuevas tierras ante el aumento demográfico e incremento de la demanda local e internacional de productos agropecuarios. El Cabildo se hizo eco de este problema y el procurador de la ciudad así lo admitía cuando afirmaba:

"El considerable aumento que han tomado las Haciendas, y havitantes de esta Campaña exijen por otra parte se proporcione puedan dilatarse, porque no pudiendo contenerse a los limites a que oy se halla reducida la Jurisdiccion de estas Fronteras ya se ve, que la necesidad precipita a muchos en la temeridad de salir fuera de ella a hacer sus Poblaciones: quedando abandonados, sin defenza y por lo mismo expuestas a ser victimas del furor de nuestros enemigos..."12!

Existían crecientes estímulos para la expansión de las actividades pecuarias que dimanaban tanto del impulso exportador centrado en los cueros como de las necesidades de abastecimiento del mercado urbano ${ }^{22}$. La ciudad experimentaba una acentuada jerarquización resultante del status de gozne privilegiado entre el Alto Perú minero y el espacio atlántico, jerarquización que se tradujo, entre múltiples manifestaciones, en un incremento significativo de su demografía. En relación a la demanda local, el procurador general estimó en: 1773 que al cabo de un año:

20-Representación de los hacendados al Cabildo, 16/9/1791. En: Acuerdos.., serie III, tomo IX, op. cit., p.645.

21- Dictamen del procurador general Manuel de Basavilbaso. Buenos Aires, 28/9/1772. Citado por Nocetti, Oscar R. y Mir, Lucio B. (1997:234)

22- Sobre la evolución del comercio exterior es interesante considerar las cifras proporcionadas por Haenke para el período 1787-1796. Véase Haenke, Tadeo (1943:86,87) 
"...en esta ciudad se consumen de quarenta á cincuenta mil cavezas de ganado..."23.

Pero gravitaban además otros alicientes vinculados al afianzamiento de un área de circulación indígena, cuya dinámica estaba regida por la coexistencia de mecanismos compulsivos y mercantiles. Grandes cantidades de ganado vacuno y caballar eran arreadas por distintas parcialidades hacia los mercados de Chile, producto tanto del robo como de los intercambios. El abigeato efectuado por traficantes españoles e indígenas era otro de los serios problemas que enfrentaban los estancieros, y la necesidad de erradicarlo obró como uno de los principales elementos justificadores para el establecimiento de la Mesta. La legislación indiana proporcionaba suficientes herramientas para combatir el delito, aunque los proyectos de ordenanzas de Mesta, basados en dicha legislación, contemplaban facultades especiales en beneficio de los hacendados, las cuales fueron defendidas por sus promotores con distintos argumentos, no siempre compartidos por las autoridades. En efecto, la proyectada sociedad se fundaba jurídicamente en las Leyes de Indias, las que autorizaban a los funcionarios a promover la creación de la Hermandad:

"...nos recomienda el Soberano en la Ley primera titulo quinto, Libro quinto de las de estos Dominios... el establecimiento de la Herm.d de la Mesta [pues] encarga á los S.res Virreyes, y Presidentes, y Audiencias, y Governadores la introduzcan donde militaze la misma razon;..." ${ }^{124}$.

En este caso se trataba de múltiples razones. Los estancieros redoblaron sus argumentos para materializar la iniciativa y reclaman el pronunciamiento de las autoridades:

"...atendiendo... lo que roban los Ladrones; y los Indios Infieles con todo lo demas que hacen el objeto de esta Junta: $Y$ entonces es oportuno el tratar en la misma Junta sobre la creación del Tribunal de la Mesta, cuya solicitud tiene pendiente este llt.e Cav.do desde el año proximo pasado de mil setecientos nobenta del qual pende el

23- Representación de Manuel de Basavilbaso al Cabildo. Buenos Aires, 4/12/1773. En: Documentos para la Historia Argentina, Abastos, tomo IV, op. cit., p.10. En realidad, la demanda de la ciudad experimentaba una sostenida expansión desde mediados del siglo XVIII, pues 25 años antes el Cabildo habia calculado "...que para El Abasto de carne de Esta Ziudad y su Jurisdiccion Se nesesitan todos los Años de veinte y sinco, A treynta mil cavesaz;...". Ver el acta del 16/9/1748 en Acuerdos..., serie II, tomo IX, 1931, p. 402 .

24- Acta del Cabildo de Buenos Aires, 12/3/1790. En: Acuerdos..., serie III, tomo IX, op. cit., p.292. 
arreglarse la Campaña y contenerse los desordenes de que abunda por faltar el oportuno remedio de unos Jueces que vigilen sin otro objeto que el de contener, y castigar los delitos, perseguir vagos, $y$ agregados que destruyen las Haciendas con el robo,...125.

\section{El rol del Estado colonial}

Al comenzar la década de 1790 el Gremio de Hacendados "no ha podido ni siquiera formalizar realmente su existencia" (Fradkin, 1987:83). Los impulsores de la Mesta consideraban que la organización del nuevo núcleo de intereses sería una eficaz alternativa institucional para enfrentar el significativo número de competidores de la campaña. Así, el Tribunal de la Mesta -en apariencia un apéndice de la proyectada Hermandad- parecía representar un reaseguro en la pugna por imponer el ansiado orden rural. El conflictivo contexto que dominaba el mundo agrario creaba condiciones favorables para ceder a las demandas de los ganaderos. Es probable que sus representantes hayan logrado sensibilizar quizá como nunca antes al virrey Loreto, quien procuró el consenso sin menoscabar la legislación. Sin embargo, la actitud conciliatoria de este virrey disimulaba mal su reticencia a consentir la aprobación de un proyecto cuyas posibles implicaciones políticas -una vez instrumentadoresultarían difíciles de prever. La presión de los hacendados a los poderes públicos había generado inquietud en la suprema autoridad virreinal, quien reputó peligroso flexibilizar los alcances de la legislación respecto a las aspiraciones de extender las facultades de estos terratenientes sobre la campaña. Si bien no existían impedimentos de orden jurídico para organizar la Mesta, las pretensiones de los hacendados parecían vulnerar las esferas de incumbencia de las autoridades, dando lugar a una soterrada colisión de intereses entre el Estado y estos productores. Según el virrey:

"Las leyes de estos reinos y las especiales reales cédulas de la materia... su observancia busqué en mi tiempo, oyendo á los proyectistas sobre estos campos solo para mejor evadirlas: para injerirse estos, unas veces figuran que solo por la manera que ellos proponen puede conseguirse que prosperen y se asegure el buen órden en ellos; $y$ otros pretenden, por el medio de privilejiarse para las corridas ó matanzas, oblar algun servicio á S.M. ó al Estado" ${ }^{126}$.

25- Memorial elevado al Cabildo por los hacendados de Buenos Aires, 16/9/1791. En: Acuerdos..., serie III, tomo IX, op. cit., pp.650-651.

26- Memoria del marqués de Loreto al virrey Nicolás de Arredondo. Buenos Aires, 10/2/1790. En: Revista del Archivo General de Buenos Aires, Bs. As., Imprenta del Porvenir, tomo IV, 1872, p. 391. 
Las prevenciones de este alto funcionario iban más allá de las resultantes de cualquier consideración fundada en legítimos intereses corporativos, pues el virrey parece deducir unos objetivos que, de concretarse, lesionarían resortes importantes para el ejercicio de su autoridad:

"Las propuestas de la primera especie nada adelantan á las reglas comunes, y traen solapado el fin de captar un absoluto poder y comision para las ejecuciones, en que enlazan el interés de su propio aprovechamiento, cuando queden dueños y dispensadores de toda aquella tierra, de que se proponen, por esta confianza, poner mas distante el celo del superior gobierno" ${ }^{\prime 27}$.

Estas prevenciones permiten explicar la actitud del sucesor del marqués de Loreto quien, como máxima autoridad del Estado, debía autorizar o impugnar las facultades requeridas por los alcaldes de Mesta. Una súplica elevada por los hacendados al virrey Arredondo a comienzos de 1793,

"...para remedio de todos estos males, y asegurar de algun modo el perpetuo subcesivo aumento de las crias de Ganados..." ${ }^{12}$

pone en evidencia algunos de los objetivos de los impulsores de la Mesta, pues en el artículo 68 se sostiene que:

"...siendo tan frequentes los Robos de Ganado Vacuno, Caballos y Mulas, y debiendose en éstos casos reagravar las penas, y aselerar su execucion p.a q.e puedan servir del error, y escarmiento; convendrá q.e el Exmo. S.or Virrey se digne autorizar á los Alc.des de Mesta, para q.e en determinados casos puedan castigar á los delinquentes conforme al espiritu de la Ley $2^{\mathrm{a}}$ Titulo 13 de la $3^{\mathrm{a}}$ Partida, y á la $6^{\mathrm{a}}$ tit 13 Libro 8 de las de Castilla, q.e hablando de los Alcaldes de la Hermandad, y delos que por Comision conocieren en los casos de ella, les dá facultad para que habida cumplida Informaz.n del delito y procediendo simplemente y de plano, sin estrepito, y figura de juicio, condenen al mal hechor en la pena que merezca, lo q.e en el dia es absolutamente necessario para contener los excesos que con tanta frequencia, y escandalo se cometen en las campañas"129.

27- Ibídem. La cursiva nos pertenece.

28- Representación de los hacendados al virrey. Buenos Aires, 29 de enero de 1793. Real Academia de la Historia, Madrid, Col. Mata Linares, XIX, f.15. Entre los peticionantes se encontraban varios "comerciantes-hacendados", como Antonio Obligado, Joaquín Cabot y Santiago Saavedra.

29- Ibídem, f.27/28. 
La súplica fue elevada por los diputados de Rincón de San Pedro, Baradero y San Nicolás, don Antonio Obligado y Juan Ignacio de San Martin; de Magdalena, don José Pereyra de Lucena y Pedro Nolasco Arroyo; de Luján, Manuel Pinazo y Joaquín Cabot; de Areco, José Antonio Otalora y Francisco Julián de Cañas; de Matanza, Ambrosio Zamudio y Manuel Iriarte; de Arrecifes Arriba, Salto y Pergamino, Santiago Saavedra y Francisco Diaz de Perafan. El memorial reiteraba el pedido de transferir mayores poderes a los hacendados ${ }^{30}$, una exigencia resistida por las autoridades. Éstas, temiendo se estructurara una organización con excesiva autonomía respecto de los poderes públicos, ya habían considerado conveniente restringir el alcance de otras atribuciones reclamadas por los ganaderos y tan sólo avalaron, por auto remitido al Cabildo en noviembre de 1792 , la realización de juntas particulares ${ }^{31}$ bajo responsabilidad de los alcaldes y con los estancieros feligreses de cada parroquia. A tales efectos el virrey concedió acotadas prerrogativas y reafirmó la vigencia de disposiciones legales requeridas por los grandes criadores de ganado, mediante las cuales se intentaba neutralizar a los competidores:

"...quando menos tengan terreno propio con media legua de frente, y una y media de fondo, sin cuio requisito á ninguno se tendra por Estanciero ni Hacendado Criador (por estar assi declarado, y publicado por Vando de Veinte y cinco de Agosto de mil setecientos setenta y cinco) en la qual Junta los que sean Hacendados criadores, y no otros propongan, traten, $y$ confieran lo que consideren que mas conviene al mejor, $y$ mas seguro arreglo que se medita, $y$ al fin de ella eligiran uno ó dos Diputados que con testimonio, ó el original de lo que alli acordaren ocurran por si, y en nombre de los que no puedan concurrir a la General que se enuncia para el dos de Enero [1793] en esta Capital..." 32.

30- En el artículo 75 del petitorio se reclamaba que "...qualquiera Criador tenga facultad, y sea auxiliado para reconocer carretas sospechosas, y cargueros de cueros, Carne, Sebo, y Grasa, y si los Conductores no llevaren Documentos que acrediten legitima procedencia, los aprehenda, y embarque los efectos dando pronto Aviso al Juez de Mesta, para que sin demora concurra, y proceda con arreglo á sus Ordenanzas, y si en éstos casos correspondiere al aprehensor alguna parte deba aplicarse para fondo de la Hermandad". Ibídem, f. 15 vta.

31- Las juntas particulares o parciales eran asambleas convocadas en cada partido y en las cuales se elegía el diputado (a veces eran dos) que acudia a la Junta General.

32- Auto del virrey Arredondo al Cabildo. Buenos Aires, 5 de noviembre de 1792. En: Documentos para Ia Historia Argentina, Abastos, tomo IV, op. cit., p. 145. Sobre la Ordenanza del 25/8/1775, dispuesta a pedido del Gremio de Hacendados, Mayo ha sostenido: "...aquellos que no poseian las tierras requeridas debian venderlas a aquellos que desearan comprarselas. Sin embargo, no existe evidencia de que esta medida fuera alguna vez seriamente implementada". (Mayo, Carlos A., 1995: 68) Cf. el fragmento correspondiente a la cita $\mathrm{N}^{\circ} 14$ de este artículo. 
Tenemos escasas noticias en relación al resultado de la Junta General del 2 de enero de 1793, aunque un punto relevante nos ha llegado a través de su eco en el Cabildo de Buenos Aires:

"...haviendose pasado al Ex.mo S.or [virrey] el acuerdo en que hizo esta representacion, [sobre la Mesta] y teniendose presente en la Junta General de Acendados celebrada a principios del año proximo pasado, tubo la satisfaccion de que el Presidente de ella, $y$ todos los concurrentes lo adoptasen, como el mas benefico y oportuno para la reparacion y aumento de dhas haciendas..."133.

Con todo, la organización de la Hermandad no prosperó. Raúl Fradkin ha interpretado el fracaso del proyecto a partir de lo que considera como insuficiente sedimentación del sector social que debía sustentarlo. (Fradkin R., 1987:86). Una lectura que compartimos. Pero es más difícil conservar el acuerdo en cuanto al limitado apoyo del Cabildo. La institución capitular avanzó todo lo que su margen de actuación permitía, pues un número apreciable de los "principales hacendados" estaba comprometido con el proyecto. Es preciso por tanto auscultar el comportamiento de otras estructuras del Estado colonial: ¿Cuál fue la posición de la máxima autoridad del Estado? La negativa del virrey -era también el presidente de la Audiencia- a autorizar la creación de un Tribunal de Mesta (organismo cuyas aspiraciones en materia de facultades judiciales excedían las permitidas a la Hermandad en tanto congregación) puede explicarse, entonces, en función de la búsqueda por parte de los hacendados de una autonomía incompatible con la existencia misma de uno de los poderes del Estado. Los estancieros procuraban monopolizar la justicia rural para disciplinar a competidores peligrosos y renuentes -gracias a las condiciones estructurales que favorecían su independencia- a someterse a la proletarización. (Mayo C., 1987)

Los grandes hacendados, con mayor grado de especialización, parecen haber sufrido graves perjuicios ante el "desorden" reinante en la campaña y, si bien fueron acompañados en su intento por los representantes de la minoría diversificada, su capacidad de actuación se vio diluida por su propia debilidad y el recelo de las autoridades ${ }^{34}$. Resulta evidente entonces que estaba todavía distante el momento en que las demandas de los estancieros empezarían a

33- Véase el acta del Cabildo de fecha 20/12/1794. En: Acuerdos..., serie III, tomo X, 1932, p.446.

34-Según Gelman a la "...elite comercial y al Estado colonial no les interesaba la consolidación del sector de los grandes estancieros y en cierta medida hasta les podia significar una molestia para la articulación comercial del hinterland rural". (Gelman, 1998:24) 
entroncarse directamente con las necesidades del Estado. En efecto, la urgencia por disponer de un exclusivo instrumento judicial puso de manifiesto la vulnerabilidad de estos ganaderos -miembros de una clase terrateniente en formación- incapaces de hegemonizar el proceso de concentración/acumulación de la tierra ${ }^{35}$ en una coyuntura que, aunque todavía tímidamente, resultaba favorable a la expansión de las actividades agropecuarias. Resistidos algunos de sus planteos por las máximas autoridades locales en virtud de unas aspiraciones que juzgaban desmedidas, los hacendados no permanecieron pasivos e hicieron oír sus quejas hasta en la misma Corte. Si bien refleja sobre todo la problemática de los nuevos intereses mercantiles (Fradkin R.,1987:79), la Representación de 1794 trasluce la inquietud ante la persistencia de un perturbado orden rural, cuya perdurabilidad también vulnera sus posibilidades de expansión: el capital comercial acumulado en el negocio saladeril y esclavista empieza a invertir en bienes raíces rurales y reclama seguridad. Una seguridad que resultó cada vez más difícil de instaurar y generaba el desagrado de estos intereses frente a las actitudes del poder local:

"...y tambien quisiéramos, que se arraigasen otras [máximas] no menos importantes en los jefes que aquí nos mandan sucesivamente, como es en primer lugar, la de sugetar á los vagos, haciendo que sean útiles á la provincia los que le son perjudiciales; porque el pueblo bien ocupado, es sin la menor duda el punto fijo de donde como líneas indefectibles parten todas las felicidades del Estado ${ }^{1136}$.

Próximo a expirar el orden colonial, hacia 1807, Mariano Moreno deploró la ausencia de una herramienta corporativa a su juicio tan eficaz para la protección de los intereses ganaderos, y reivindica las bondades de la institución medieval en la lucha contra el abigeato:

"La Mesta establecida en España no tiene otro obgeto que fomentar el procreo de ganados, é impedir los robos que pudieran entorpecer su fomento, y perturbar al propietario en su tranquila posesion. Tenemos la desgracia de carecer en esta Provincia de un Consejo tan util y necesario, á pesar de las Leyes de Indias que tan encarecidamente encargan su establecimiento,..." ${ }^{37}$.

35- Indispensable para obligar a los sectores subalternos y marginales a ingresar al mercado de trabajo. 36- Representación elevada al ministro Diego Gardoqui [1794]. En: La Revista de Buenos Aires, Bs. As., Imprenta de Mayo, tomo XI, 1866, p.40.

37- Alegato de Moreno en un juicio por robo de ganado [1807]. En: Archivo General de la Nación, Papeles del Archivo, Bs. As., Guillermo Kraft Ltda., 1942, p.22. 
Las autoridades virreinales, aun cuando estaban dispuestas a potenciar las acciones represivas en procura de resguardar el orden y la seguridad de la campaña, resistieron transferir facultades judiciales que habrían comprometido no sólo el equilibrio de la estructura institucional, sino que hubieran sentado precedentes de autonomía sectorial cuyas consecuencias políticas resultaba imperioso prevenir. En efecto, nada parece haber suscitado probablemente mayor influencia en el virrey Arredondo que las prevenciones planteadas por su antecesor. El marqués de Loreto había evaluado negativamente el comportamiento corporativo de los grandes intereses ganaderos, sobre los cuales no dudó en asegurar que:

"Asi como he meditado cuanto es justo en favor de los hacendados, conozco la necesidad de ocurrir á sus abusos en mas puntos, que llevo indicados: tienen estos unos apoderados que, debiendo ceñirse á representar sus acciones, les adverti alguna vez tan autorizados, como si se hubiesen sustituido por el gobierno, y este se hallase inhivido; pidiendo otras veces auxilio, mas bien que providencias; y poniéndose las leyes por si mismas, mas bien que recibiéndolas del mando, á quien toca nivelarlas en su ejecucion con el bien público y del Estado..." ${ }^{138}$.

La aprobación prestada por el Cabildo a la organización de la Mesta resultó definitivamente inaceptable para las estructuras superiores del Estado. Pero en realidad lo inadmisible no parece haber sido la Mesta en tanto corporación sino ciertos privilegios reclamados amparándose en la necesidad de la Mesta: a partir de ella se intentó instaurar un tribunal cuasi privado que venía a subrogar el monopolio de la violencia inherente a los poderes públicos, una prerrogativa que infringía las atribuciones previstas por la legislación indiana. Las pretensiones de los grandes hacendados chocarían una y otra vez con la reticencia de esos poderes, empeñados en privilegiar cierta función de equidistancia entre los diferentes grupos de presión, conforme a la política impulsada por el Estado metropolitano borbónico. Los fines perseguidos con la Mesta diluían la actuación del Estado en la campaña e iban más allá del peso específico que sus promotores representaban en el juego de fuerzas del Buenos Aires tardocolonial, y por ello resultó un proyecto inviable. Sólo después de 1820, en pleno boom ganadero, los intereses de los estancieros habrán de entroncarse férrea y duraderamente con las necesidades y objetivos del Estado bonaerense.

38- Memoria del virrey Loreto a Nicolás de Arredondo. Buenos Aires, 10/2/1790. En: Revista del Archivo..., tomo IV, op. cit., p.393. La cursiva nos pertenece. 


\section{Referencias bibliográficas}

*AZCUY AMEGHINO, Eduardo (1988), "Economía y sociedad colonial en el ámbito rural bonaerense". En: Economía e Historia, Bs. As., Editorial Tesis.

*FRADKIN, Raúl O. (1987), "El Gremio de Hacendados en Buenos Aires durante la segunda mitad del siglo XVIII". En: Cuadernos de Historia Regional, No8, Luján.

*GARAVAGLIA, Juan Carlos (1993), "La agricultura del trigo en las estancias de la campaña bonaerense: tecnología y empresas productivas (1750-1815)". En: Raúl Mandrini y Andrea Reguera (Comps.) Huellas en la tierra. Indios, agricultores y hacendados en la pampa bonaerense, Tandil, IEHS.

*GARAVAGLIA, Juan Carlos y GELMAN, Jorge Daniel (1989), El mundo rural rioplatense a fines de la época colonial: estudios sobre producción y mano de obra, Bs. As., Fundación Simón Rodriguez, Editorial Biblos.

*GELMAN, Jorge D. (1989), "Sobre el carácter del comercio colonial y los patrones de inversión de un gran comerciante en el Río de la Plata del siglo XVIII". En: Boletín del Instituto de Historia Argentina y Americana Dr. Emilio Ravignani, Bs. As., tercera serie, $\mathrm{N}^{0} 1$.

*GELMAN, Jorge (1998), Campesinos y estancieros. Una región del Río de la Plata a fines de la época colonial, Bs. As., Editorial Los Libros del Riel.

*GIBERTI, Horacio (1986), Historia económica de la ganadería argentina, Bs. As., Ediciones Solar. (La primera edición es de 1954)

*HAENKE, Tadeo (1943), Viaje por el Virreinato del Rio de la Plata [1809], Bs. As., Emecé Editores.

*HALPERIN DONGHI, Tuliọ (1979), Revolución y guerra, Siglo XXI, México. *HALPERIN DONGHI, Tulio (1994), "La expansión ganadera en la campaña de Buenos Aires (1810-1852)". En: Di Tella, Torcuato y Halperin Donghi, Tulio. [Eds.] Los fragmentos del poder, Bs. As., Juan Álvarez, 1969; Revolución y guerra. Formación de una élite dirigente en la Argentina criolla, Bs. As., Siglo XXI.

*KLEIN, Julius (1990), La Mesta. Estudio de historia económica española 1273-1836, Madrid, Alianza Universidad. La primera edición castellana es de 1936.

*KONETZKE, Richard (1983), América latina. II. La época colonial, Madrid, Historia Universal Siglo XXI, vol.22.

*MARQUIEGUI, Dedier N. (1990), "Estancia y poder político en un partido de la campaña bonaerense (Luján, 1756-1821)". En: AA.VV., Estructuras sociales y mentalidades en América Latina. Siglos XVII y XVIII, Bs. As., Fundación Simón Rodriguez, Editorial Biblos 
*MAYO Carlos A. (1995), Estancia y sociedad en la pampa, 1740-1820, Bs. As., Editorial Biblos.

*MAYO, Carlos A. (1984), "Estancia y peonaje en la región pampeana en la segunda mitad del siglo XVIII". En: Desarrollo Económico, Bs. As., vol.23, $\mathrm{N}^{\circ}$ 92, enero-marzo.

*MAYO, Carlos A. (1987), "El dilema de la economía rural rioplatense durante la época colonial". En: Anuario IEHS, №2, Tandil, Universidad Nacional del Centro de la Provincia de Buenos Aires.

* MONTOYA, Alfredo Juan (1984), Cómo evolucionó la ganadería en la época del Virreinato, Bs. As., Editorial Plus Ultra.

*MORENO, José L. (1993), "Población y sociedad en el Buenos Aires rural a fines del siglo XVIII". En: Juan Carlos Garavaglia y José Luis Moreno (Comps.) Población, sociedad, familia y migraciones en el espacio rioplatense. Siglos XVIII y XIX, San Martín, Editorial Cántaro.

*NELLAR, Fued G. (1973) en Política seguida con el abórigen (1750-1819), Bs. As., Círculo Militar, Biblioteca del Oficial, tomo I.

*NOCETTI, Oscar R. y MIR, Lucio B. (1997), La disputa por la tierra. Tucumán, Río de la Plata y Chile, 1531-1822, Bs. As., Editorial Sudamericana. * ROCK, David (1994), Argentina 1516-1987. Desde la colonización española hasta Raúl Alfonsín, Bs. As., Alianza Editorial

*SALVATORE Ricardo y BROWN Jonathan C. (1993), "Comercio y proletarización en la Banda Oriental tardo-colonial: la Estancia de las Vacas, 17911805". En: Raúl O. Fradkin (Comp.) La historia agraria del Río de la Plata colonial. Los establecimientos productivos, Bs. As., Centro Editor de América Latina. 